\title{
Autosomal Dominant Polycystic Disease of the Kidneys as one of the Primary Diseases to the Patients on the Chronic Dialysis Program
}

\author{
Damir Pelicic*1,2 \\ ${ }^{1}$ Clinical Center of Montenegro, Podgorica, Montenegro \\ ${ }^{2}$ Faculty of Medicine, University of Montenegro, Podgorica, Montenegro
}

*Corresponding author: Damir Pelicic, Center for Science, Clinical Center of Montenegro, Ljubljanska bb, Podgorica 20000, Montenegro

\begin{tabular}{lll}
\hline ARTICLE INFO & & ABSTRACT \\
\cline { 1 - 1 } $\begin{array}{l}\text { Received: November 06, } 2020 \\
\text { Published: November 16, } 2020\end{array}$ & $\begin{array}{l}\text { Citation: Damir Pelicic. Autosomal Dominant Polycystic Disease of the Kidneys as one of } \\
\text { the Primary Diseases to the Patients on the Chronic Dialysis Program. Biomed J Sci \& Tech } \\
\text { Res 31(5)-2020. BJSTR. MS.ID.005176. }\end{array}$
\end{tabular}

\section{Editorial}

With this notice I would like to remind all of us to an important topic such as Autosomal dominant polycystic kidney disease which is on the fourth position between causes of the chronic renal failure and it's very rare in Montenegro. It is significant health and economic burden for the community and annual expenses for provision of services and therapy for kidney patients inside European Union (EU) and they are estimated to 1,2 billion euros [1]. Polycystic kidney disease (PKD) is a life-threatening genetic disorder characterized by appearance of the numerous numbers of cysts filled by liquid first in the kidneys and then in the other organs such as liver and pancreas. PKD includes one of two genetical disorders: autosomal recessive polycystic kidneys disease (ARPKD) and autosomal dominant polycystic kidneys disease (ADPKD) $[2,3]$. Autosomal dominant polycystic kidney disease (ADPKD) is monogenic kidney disease. It is characterized by the development of kidney cysts, hypertension and at the end kidney disease in its final stage. It seems that the prevalence in Europe is lower than 1 in 2000 so the European agency for medications (EMA) classified it as rare one. Beside kidney cysts, pancreas cysts are common too (to more than older than 35) $[4,5]$.

APKD is described for the first time 300 years ago. Population epidemiological studies determined through autopsies influence of ADPKD to 1 of 400 to 1000 live born or 12.5 million people around the world. Other studies are based on the information from the clinical register suggesting lower rates of prevalence in the range from 1 to 543 to 1 to 4000 . APDK influences both sex and it appears in all ethnic groups. It falls on it $5 \%$ to $10 \%$ of the cases of ESRD what makes it the fourth leading global cause of the kidney insufficiency [5]. ADPKD is mostly hereditary kidney disease characterized by growing numbers of cysts in the kidneys [6]. Today around 7-8 \% of all chronic kidney patients with terminal kidney insufficiency in Europe have PKD [7]. Although it is offered a couple of directives about predictions of disease development the gold standard still does not exist [8]. Beside radiological examinations and set up of the diagnosis the most important is to take family amnesia in details. During palpation a doctor finds out enlarge kidneys from both sides and through functional tests sees supraphysiological proteinuria which is not of nephrotic rank. Cysts in the liver are present to the $50 \%$ of the patients and they are more common to the female patients.

The number of the patients involved in a chronic hemodialysis program of The Clinical Centre of Montenegro in Podgorica is around 65 . From that number 35 patients are male $(53,85 \%)$ and 30 patients are female $(46,15 \%)$. The primary cause of the disease to the patients on the hemodialysis is hypertension to 26 of them $(40 \%)$ to the other 17 patients $(26,15 \%)$ have polycystic kidney disease. It is very rare in the world that between all the causes of kidney insufficiency polycystic disease on the second place. On 
the third place is diabetes mellitus 2 what includes $13(20 \%)$ of the patients and on the second place are the other diseases to 9 patients $(13,85 \%)$. Symptoms and seriousness of ADPKD differ from person to person and is very har to make some long-distance predictions. ADPKD is a slow progressive condition what means that symptoms get worse. One half of the persons with ADPKD will develop kidney insufficiency in adult time what demands one of the replacement modality of kidney function what means dialysis, peritoneal dialysis, or kidney transplantation $[9,10]$. Prenatal diagnostics, as part of genetic information, provides the possibility of prenatal diagnosis of the disease and the provision of objective genetic counseling in accordance with ethical principles [11]. There isn't any specific therapy for this disease however complications are cured and it is important to develop disease in the early stage at the level of the primary health care in intention to prevent further complications and improve life quality.

\section{References}

1. Mao Z, Chong J, Ong ACM (2016) Autosomal dominant polycystic kidney disease: recent advances in clinical management F1000Research, 5(F1000 Faculty Rev): 2029.

2. Thong KM, Ong AC (2013) The natural history of autosomal dominant polycystic kidney disease: 30- year experience from a single centre. QJM: monthly journal of the Association of Physicians 106(7): 639-646.

\section{ISSN: 2574-1241}

DOI: $10.26717 /$ BJSTR.2020.31.005176

Damir Pelicic. Biomed J Sci \& Tech Res

(C) This work is licensed under Creative

Submission Link: https://biomedres.us/submit-manuscript.php
3. Pirson Y (2010) Extrarenal manifestations of autosomal dominant polycystic kidney disease. Advances in chronic kidney disease 17(2): 173-180.

4. Chapman AB, Devuyst O, Eckardt K, Ron TG, Tess H, et al. (2015) Autosomal dominant polycystic kidney disease (ADPKD): executive summary from a Kidney Disease: Improving Global Outcomes (KDIGO) Controversies Conference. Kidney Int 88(1): 17-27.

5. Torres VE, Harris PC, Pirson Y (2007) Autosomal dominant polycystic kidney disease. Lancet 369: 1287-1301.

6. Ong AC, Devuyst O, Knebelmann B, Gred W (2015) Autosomal dominant polycystic kidney disease: the changing face of clinical management. Lancet 385(9981): 1993-2002.

7. Grantham JJ (2008) Clinical practice. Autosomal dominant polycystic kidney disease. N Engl J Med 359(14): 1477-85.

8. (2020) Acquired Cystic Kidney Disease, National Institute of Diabetes and Digestive and Kidney Diseases, NIH.

9. Irazabal MV, Rangel LJ, Bergstralh EJ, Osborn SL, Armon AJ, et al. (2015) Imaging classification of autosomal dominant polycystic kidney disease: a simple model for selecting patients for clinical trials. J Am Soc Nephrol 26(1): 160-172.

10. Cornec Le Gall E, Alam A, Perrone RD (2019) Autosomal dominant polycystic kidney disease. Lancet 393(10174): 919-935.

11. Judita L (2017) Polycystic kidney disease, Master's thesis. University of Zagreb, School of Medicine, Croatia.

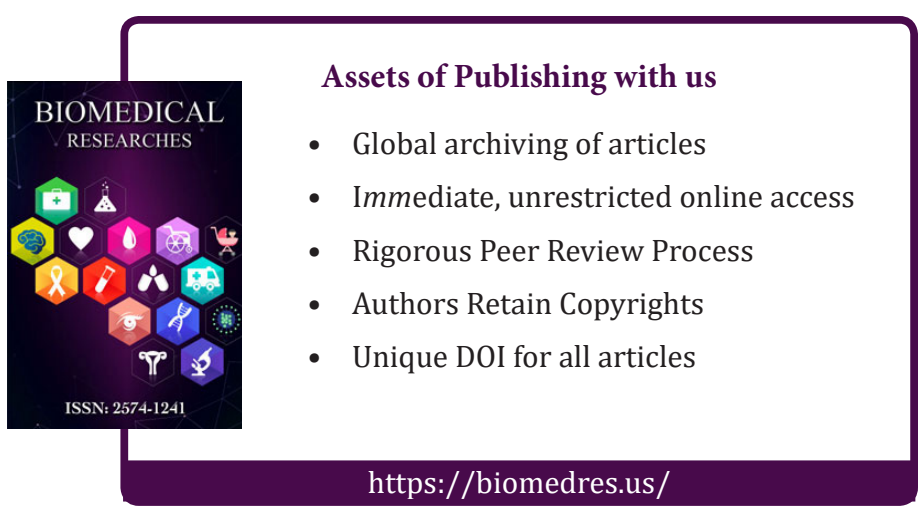

